\title{
Cold snare polypectomy reduced delayed postpolypectomy bleeding compared with conventional hot polypectomy: a propensity score-matching analysis
}

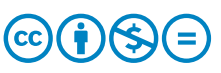

\author{
Authors \\ Takeshi Yamashina, Manabu Fukuhara, Takanori Maruo, Gensho Tanke, Saiko Marui, Ryota Sada, Mio Taki, Yoshiaki \\ Ohara, Azusa Sakamoto, Shinichiro Henmi, Yugo Sawai, Sumio Saito, Norihiro Nishijima, Akihiro Nasu, Hideyuki \\ Komekado, Akira Sekikawa, Masanori Asada, Takehiko Tumura, Ryuichi Kita, Toru Kimura, Yukio Osaki
}

Institution

Department of Gastroenterology and Hepatology, Osaka Red Cross Hospital, Osaka, Japan

submitted 21.8.2016

accepted after revision 10.2 .2017

Bibliography

DOI https://doi.org/10.1055/s-0043-105578 |

Endoscopy International Open 2017; 05: E587-E594

(c) Georg Thieme Verlag KG Stuttgart · New York ISSN 2364-3722

Corresponding author

Takeshi Yamashin, Department of Gastroenterology and Hepatology, Osaka Red Cross Hospital, Osaka, Japan, 30 Fudegasaki, Tenouji, Osaka 543-8555, Japan

Fax: (+81) 6-(6774)-5131

take8047@hotmail.com

\section{ABSTRACT}

Background and study aims Cold snare polypectomy (CSP) for small colorectal polyps has lower incidence of adverse events, especially delayed postpolypectomy bleeding (DPPB). However, few data are available on comparisons of the incidence of DPPB of CSP and hot polypectomy (HP). The aim of this study was to evaluate the incidence of
DPPB after CSP and compare it with that of HP. A propensity score model was used as a secondary analysis.

Patients and methods This was a retrospective cohort study conducted in a single municipal hospital. We identified 539 patients with colorectal polyps from $2 \mathrm{~mm}$ to 11 $\mathrm{mm}$ in size who underwent CSP (804 polyps in 330 patients) or HP (530 polyps in 209 patients) between July 2013 and June 2015.

Results There were no cases of DPPB in the CSP group. Conversely, DPPB occurred in 4 patients (1.9\%) after HP, resulting in a significant difference between the CSP and HP groups $(0.008 \%$ vs $0 \%, P=0.02)$. Propensity score-matching analysis created 402 matched pairs, yielding a significantly higher DPPB rate in the HP group than CSP group ( $0.02 \%$ vs $0 \%, P=0.04)$. However, significantly more patients in the CSP group had unclear horizontal margins that precluded assessment ( 83 vs 38 cases, $P<0.001$ ). The retrieval failure rate was significantly higher in the CSP group than in the HP group ( $3 \%$ vs $0.7 \%, P=0.01$ ).

Conclusions DPPB was less frequent with CSP than HP, as selected by the propensity score-matching model. Our findings indicate that CSP is recommended polypectomy in daily clinical setting. However, special care should be taken during polyp retrieval and horizontal margin assessment, and these issues could be taken into account in follow-up after CSP.

\section{Introduction}

Colorectal carcinoma (CRC) is the fourth-most-common cause of cancer-related mortality worldwide [1] , and it is the thirdmost-common cancer, with nearly 1.4 million new cases in 2012 [2] . Most cases originate from adenomas [3] and their removal reduces the risk of death from CRC [4]. Therefore, if adenomas and cancers are detected early in their development, they can be cured by endoscopic therapy.

Hot polypectomy $(\mathrm{HP})$, including hot snare polypectomy, endoscopic mucosal resection (EMR) and hot biopsy polypectomy, are the most commonly performed endoscopic therapies with electrocautery to remove colorectal polyps. However, two major adverse events (AEs), delayed post-polypectomy bleeding (DPPB) and perforation have remained an issue. In previous reports, the incidence of DPPB of HP was $0.6 \%$ to $2 \%$ [5-10]. Moreover, polyp size, shape, and location are risk factors for DPPB $[6,10]$.

In contrast, as far back as 20 years ago, cold snare polypectomy (CSP) for small colorectal polyps has been reported to be a safe and effective polyp removal method without electrocautery [11-13]. This method is also superior to conventional polypectomy in terms of procedure time [14]. Thus, currently, CSP has gained notoriety. Moreover, the incidence of DPPB was re- 
ported to be $0 \%$ to $1.8 \%$ for CSP in previous prospective studies [15-19], which tends to be lower than that of HP even in patients that continued to receive anticoagulant treatment [17]. However, a previous study included only a small number of patients, and few studies have compared the incidence of DPPB of CSP and HP in daily clinical setting.

Randomized controlled trials are the most effective way of scientifically testing new medical interventions. However, the rate of DPPB is relatively low, and many cases are needed to conduct randomized controlled trials. Paspatis et al. conducted a randomized controlled trial comparing CSP with hot snare HP in the occurrence of DPPB [19]. However, they didn't stratify by polyp size, and in it was significantly larger in the HP group than the CSP group and there was no DPPB in either group. Recently, propensity score matching has become a popular alternative to randomized controlled trials [20]. We therefore hypothesized that it would be more effective to use propensity score matching analysis to compare CSP directly with HP. The aim of this study was to evaluate the incidence of DPPB after colorectal CSP and compare it with that after HP. Additionally, we performed secondary analysis with a propensity score model.

\section{Patients and methods}

\section{Patients}

This retrospective cohort study was performed in a single municipal hospital. We identified consecutive patients with colorectal polyps from $2 \mathrm{~mm}$ to $11 \mathrm{~mm}$ in size who underwent CSP or HP between July 2013 and June 2015 in our prospectively maintained database of Osaka Red Cross Hospital, and enrolled them into this analysis. Before February 2014, we mainly performed HP and after February 2014, we mainly performed CSP. Patients with colorectal polyps larger than $5 \mathrm{~mm}$ who were recommended to undergo polypectomy and all polyps resected endoscopically during screening colonoscopies were included in the study. Patients who underwent colorectal HP and CSP procedures during operation or patients with perforation during the procedure were excluded. This manuscript was prepared according to the Strengthening the Reporting of Observational Studies in Epidemiology (STROBE) Statement [21].

\section{Endoscopic procedure and perioperative management}

CSP or HP was performed under intravenous sedation with midazolam. During colonoscope withdrawal, polyp location was documented and size was measured using biopsy forceps with a 2.2-mm outer diameter or snares with an outer diameter of $11 \mathrm{~mm}$ to $20 \mathrm{~mm}$. The phenotypes of polyps were classified according to the Paris classification [22]. Before polypectomy, chromoendoscopy or magnifying endoscopy was performed to exclude the non-neoplastic lesions. The CSP was performed with a videoendoscope (CF-HQ290, PCF-PQ260L, Olympus Medical Systems, Tokyo, Japan) for small $(\leq 11 \mathrm{~mm})$ polypoid lesions using Profile ${ }^{\mathrm{TM}}$ Polypectomy Snares (Boston Scientific Japan, Tokyo, Japan) by 15 experienced colonoscopists who have sufficient expertise and experience of colorectal polypectomy. They all thoroughly experienced CSP or otherwise specialists al- ways supervised the procedure in introduction period. The polyp was snared, including normal surrounding mucosa and the snare was closed for transection of the polyp without electrocautery. HP was performed with a similar type of videoendoscope used for polypoid lesions. The same colonoscopists that performed CSP mainly used the XEMEX Bipolar Snare S DRAGONARETM (Xemex, Tokyo, Japan) to perform HP. As for EMR, normal saline is injected into the submucosa before excision. The Intelligent Cut and Coagulation 200 (ERBE Elektromedizin, Tübingen, Germany) or VIO $300 \mathrm{D}$ (ERBE) was used as a power source for electrical bipolar cutting and bipolar coagulation, and all participant endoscopists used the same setting. Before February 2014, we conventionally underwent clipping in most HP cases. From that time onwards, the mucosal defects after CSP or HP were large or if blood was spurting immediately, the mucosal defect was closed using endoscopic clips. Usually, CSP was performed as an outpatient procedure. And as many other Japanese hospitals, HP usually required a two-day hospitalization. In general, most of Japanese patients who undergo polypectomy or EMR are hospitalized for a few days. All patients underwent postoperative follow-up hospital visits about two weeks after polypectomy.

\section{Propensity score matching analysis}

To reduce the possibility of selection bias and to identify control subjects, we performed propensity score matching with a ratio of $1: 1$ and nearest neighbor matching without replacement within a caliper width of 0.02 and the polyps for which the propensity score could not be matched because of a greater caliper distance were excluded from further analysis. To estimate the propensity score, we used a logistic regression model. Factors related to DPPB have been previously reported to be polyp sizes, polyps located in the right-sided colon and polyp shape $[6,10]$. Hence, variables included in the propensity score model were polyp size, polyp location (right-sided colon vs left-sided colon) and polyp shape (Ip and Isp vs Is and IIa).

\section{Data analysis and definition of outcomes}

The procedural details were recorded prospectively in a database and their medical records were thoroughly investigated. The collected data included patient age, gender (male or female), location (cecum, ascending colon, transverse colon, descending colon, sigmoid colon, or rectum), tumor size, morphological type, and histological type (adenoma or serrated lesions, or carcinoma). The characteristics of lesions in the CSP group were compared with those in the HP group. Primary endpoint of this study was DPPB rate after colorectal CSP and compare it with that after HP. Other AEs, retrieval failure rate and horizontal margin were evaluated as secondary endpoints. DPPB was defined as hemochezia occurring $>24$ hours after colorectal polypectomy that required an endoscopic hemostatic procedure.

\section{Statistical analysis}

The Fisher's exact test or $x^{2}$ test was used for analysis of categorical data. Quantitative data were compared using the Student's $t$ test or Mann-Whitney $U$ test. $P<0.05$ (two-sided) was 


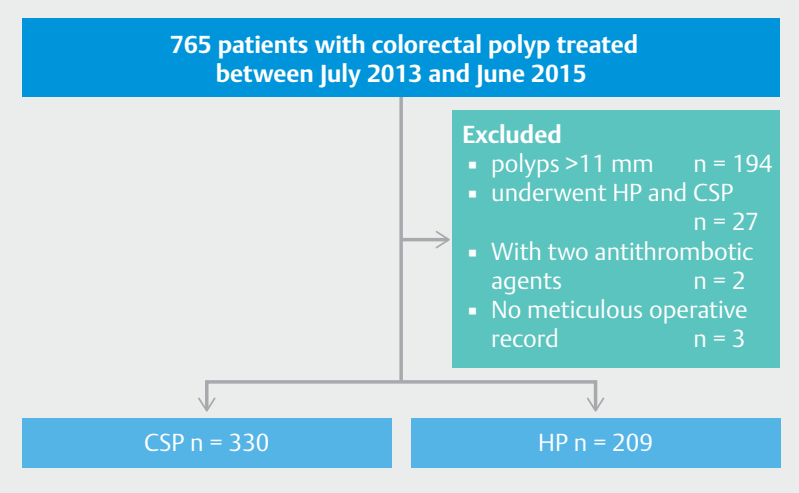

Fig. 1 Flow diagram. CSP, cold snare polypectomy; HP, hot polypectomy

considered significant. All statistical analyses were carried out using SPSS statistics version 23 (SPSS, Chicago, IL, USA).

\section{Results}

\section{Baseline data}

During the study period, 765 patients with colorectal polyps were treated by CSP or HP at the Osaka Red Cross Hospital during the study period. A total of 226 patients were excluded from the analysis because they had polyps $>11 \mathrm{~mm}(\mathrm{n}=194)$, underwent another colorectal HP at the same time $(n=27)$, continued treatment with two antithrombotic agents $(n=2)$ or had no meticulous operative record $(n=3)$. A flow diagram of the participants is shown in - Fig. 1. In total, 804 polyps in 330 patients were included in our analysis of CSP group, and the baseline characteristics are presented in $>$ Table 1. Patients comprised 196 men and 134 women with a median age (range) of $68(27-91)$ years. The median resected tumor size (range) was $4(2-11) \mathrm{mm}$, and the lesions were located in the cecum, ascending colon, transverse colon, descending colon, sigmoid colon, and rectum in 50, 197, 203, 82, 206, and 66 cases, respectively ( $\vee$ Table 2 ). Eighteen patients received antithrom- botic agents: aspirin; 8, clopidogrel; 3, cilostazol; 2, aspirin-dialuminate; 1 , sarpogrelate; 1 , limaprost alfadex; 1 , apixaban; 1 , rivaroxaban; 1 . Conversely in total 530 polyps in 209 patients were included in our analysis of HP group (Polypectomy: 329, EMR: 181, Hot biopsy: 20), and the baseline characteristics are presented in Table 1. Patients comprised 142 men and 69 women with a median age (range) of $66(30-91)$ years. The median resected tumor size (range) was $5(2-11) \mathrm{mm}$, and the lesions were located in the cecum, ascending colon, transverse colon, descending colon, sigmoid colon, and rectum in $28,105,123,57,169$, and 49 cases, respectively. In the HP group, eight patients discontinued the antithrombotic therapy and none of the patients continued the antithrombotic therapy. No differences were observed in gender, age, location or morphology between the CSP and HP groups ( $>$ Table 2 ).

\section{Procedure-related outcomes}

In this study, there were no cases of DPPB in the CSP group. Otherwise, although two cases were used clips for closure of the mucosal defect, DPPB occurred in four patients $(1.9 \%)$ who underwent HP in different colonoscopists for colorectal polyps, resulting in a significant difference between the CSP and HP groups $(0.008 \%$ vs $0 \%, P=0.02)$. However, the HP group had a significantly larger median resected polyp size ( $4 \mathrm{~mm}$ vs $5 \mathrm{~mm}, P=0.01)$. There was no statistically significant difference in histological type of polyp or assessment of the horizontal margin between the groups. The HP group had a significantly larger number of clips used for closure of the mucosal defect or hemoclip ( $79 \%$ vs $6 \%, P<0.001$ ). The retrieval failure rate was significantly higher in the CSP group than in the HP group ( $4 \%$ vs $1 \%, P=0.001$ ). All DPPB cases were managed conservatively with the endoscopic hemostatic procedure and no other serious AEs, such as perforation or postpolypectomy syndrome, were observed in either group.

\section{Procedure-related outcomes after propensity score matching}

The matching factors and treatment outcomes between the CSP and HP groups after propensity score matching are shown in $>$ Table 3. Four hundred and two pairs were matched. Ten

\begin{tabular}{|c|c|c|c|}
\hline & CSP group & HP group & $P$ value \\
\hline Patients & 330 & 209 & $0.07^{1}$ \\
\hline - Male (\%) & $196(59 \%)$ & $142(68 \%)$ & \\
\hline - Female (\%) & $134(41 \%$ & $69(32 \%)$ & \\
\hline Median age (range, years) & $68(27-91)$ & $66(30-91)$ & $1.0^{2}$ \\
\hline Antithrombotic therapy & & & $<0.001^{1}$ \\
\hline - None or discontinuation & 312 & 209 & \\
\hline - Continuation & 18 & 0 & \\
\hline $\begin{array}{l}\text { CSP, cold snare polypectomy; } \\
{ }^{1} \mathrm{X}^{2} \text { test } \\
{ }^{2} \text { Student's } t \text { test. }\end{array}$ & & & \\
\hline
\end{tabular}


- Table 2 Baseline characteristics of lesions.

\begin{tabular}{|c|c|c|c|}
\hline & $\begin{array}{l}\text { CSP group } \\
(n=804)\end{array}$ & $\begin{array}{l}\text { HP group } \\
(n=530)\end{array}$ & $P$ value \\
\hline Location & & & $0.3^{1}$ \\
\hline - Cecum & $50(6 \%)$ & $28(5 \%)$ & \\
\hline - Ascending colon & $197(25 \%)$ & $105(20 \%)$ & \\
\hline - Transverse colon & $203(25 \%)$ & $122(23 \%)$ & \\
\hline - Descending colon & $82(10 \%)$ & $57(11 \%)$ & \\
\hline - Sigmoid colon & $206(26 \%)$ & $169(32 \%)$ & \\
\hline - Rectum & $66(8 \%)$ & $49(9 \%)$ & \\
\hline Morphology & & & $0.6^{1}$ \\
\hline - Pedunculated type & $16(2 \%)$ & $24(5 \%)$ & \\
\hline - Semipedunculated type & $130(16 \%)$ & $132(25 \%)$ & \\
\hline - Sessile type & $548(68 \%)$ & $239(45 \%)$ & \\
\hline - Superficial elevated type & $110(14 \%)$ & $130(25 \%)$ & \\
\hline - Superficial depressed type & 0 & $2(0.4 \%)$ & \\
\hline - Submucosal tumor & 0 & $3(0.6 \%)$ & \\
\hline Median tumor size (range, mm) & $4(2-11)$ & $5(2-11)$ & $0.01^{2}$ \\
\hline Histological type & & & $0.1^{1}$ \\
\hline - Adenocarcinoma & $0(0 \%)$ & $12(2 \%)$ & \\
\hline - Adenoma & $685(85 \%)$ & $445(84 \%)$ & \\
\hline - Hyperplastic polyp & $52(6 \%)$ & $37(7 \%)$ & \\
\hline - Sessile serrated adenoma polyp & $11(1 \%)$ & $11(2 \%)$ & \\
\hline - Traditional serrated polyp & $2(0.2 \%)$ & 0 & \\
\hline - Non-neoplastic lesion & $21(3 \%)$ & $16(3 \%)$ & \\
\hline - Retrieval failure & $33(4 \%)$ & $6(1 \%)$ & \\
\hline Retrieval & & & $0.001^{3}$ \\
\hline - Success & $771(96 \%)$ & $524(99 \%)$ & \\
\hline - Failure & $33(4 \%)$ & $6(1 \%)$ & \\
\hline Horizontal margin ${ }^{4}$ & & & $0.1^{1}$ \\
\hline - Clear & $530(76 \%)$ & $424(80 \%)$ & \\
\hline - Positive & 10 & 1 & \\
\hline - Negative & 520 & 423 & \\
\hline - Unclear & $168(24 \%)$ & $106(20 \%)$ & \\
\hline Clipping for disclosure & & & $<0.001^{1}$ \\
\hline - None & $752(94 \%)$ & $109(21 \%)$ & \\
\hline - Clipping & $52(6 \%)$ & $421(79 \%)$ & \\
\hline \multicolumn{4}{|c|}{$\begin{array}{l}\text { CSP, cold snare polypectomy; HP, hot snare polypectomy } \\
{ }^{1} \mathrm{X} 2 \text { test } \\
{ }^{2} \text { Mann-Whitney } U \text { test } \\
{ }^{3} \text { Fisher's exact test } \\
{ }^{4} \text { only adenomatous lesions were analyzed. }\end{array}$} \\
\hline
\end{tabular}


- Table 3 Characteristics of the patients and lesions after propensity score-matching.

\begin{tabular}{|c|c|c|c|}
\hline & CSP group & HP group & $P$ value \\
\hline Patients & 231 & 177 & \\
\hline " (Male/Female) & $(138 / 93)$ & $(122 / 55)$ & \\
\hline Antithrombotic therapy & & & $<0.006^{1}$ \\
\hline - None or discontinuation & 221 & 177 & \\
\hline - Continuation & 10 & 177 & \\
\hline Polyps & 402 & 402 & \\
\hline Location & & & $1.0^{2}$ \\
\hline - Right-side colon & $208(52 \%)$ & $208(52 \%)$ & \\
\hline - Left-side colon & $168(42 \%)$ & $168(42 \%)$ & \\
\hline - Rectum & $26(6 \%)$ & $26(6 \%)$ & \\
\hline Morphology & & & $1.0^{2}$ \\
\hline - Pedunculated type & $9(2 \%)$ & $9(2 \%)$ & \\
\hline - Semipedunculated type & $82(20 \%)$ & $82(20 \%)$ & \\
\hline - Sessile type & $221(55 \%)$ & $221(55 \%)$ & \\
\hline - Superficial elevated type & $90(22 \%)$ & $90(22 \%)$ & \\
\hline Median tumor size (range, $\mathrm{mm}$ ) & $5(2-11)$ & $5(2-11)$ & $1.0^{3}$ \\
\hline Retrieval & & & $0.01^{1}$ \\
\hline - Success & $388(97 \%)$ & $399(99 \%)$ & \\
\hline - Failure & $14(3 \%)$ & $3(1 \%)$ & \\
\hline Horizontal margin ${ }^{4}$ & & & $<0.001^{2}$ \\
\hline - Clear & $282(77 \%)$ & $325(90 \%)$ & \\
\hline - Positive & 8 & 1 & \\
\hline - Negative & 274 & 324 & \\
\hline - Unclear & $83(23 \%)$ & $38(10 \%)$ & \\
\hline Clipping for disclosure & $38(9 \%)$ & $325(81 \%)$ & $<0.001^{2}$ \\
\hline - None & $364(91 \%)$ & $77(19 \%)$ & \\
\hline \multicolumn{4}{|c|}{$\begin{array}{l}\text { CSP, cold snare polypectomy; HP, hot snare polypectomy } \\
{ }^{1} \text { Fisher's exact test } \\
{ }^{2} \mathrm{X}^{2} \text { test } \\
{ }^{3} \text { Mann-Whitney } U \text { test } \\
{ }^{4} \text { only adenomatous lesions were analyzed. }\end{array}$} \\
\hline
\end{tabular}

patients received antithrombotic agents in CSP group. With regard to treatment outcomes, the DPPB rate for colorectal polyps was significantly higher in the HP group than in the CSP group $(0.02 \%$ vs $0 \%, P=0.04)$ ( $\vee$ Table 4$)$. The HP group had a significantly larger number of clips used for closure of the mucosal defect or hemoclip ( $81 \%$ vs $9 \%, P<0.001$ ). Significantly more patients in the CSP group had unclear horizontal margin precluding its assessment ( 83 vs 38 cases, $P<0.001$ ). The retrieval failure rate was significantly higher in the CSP group than in the HP group ( $3 \%$ vs $0.7 \%, P=0.01$ ).

\section{Discussion}

CSP is a polypectomy method that has gained considerable notoriety in recent years, as it is a safe and efficient method for small polyps. In this study, we removed 804 polyps, easily and safely, including those of 18 patients (73 polyps) on single antithrombotic therapy. There was no increase in the rate of AEs, and particularly, there were no cases of DPPB in the CSP group. Furthermore, we used propensity score-matching analysis between the CSP and HP groups to reduce or minimize the effects of sampling bias (location, size and morphology) in non-randomized studies [20]. As a result, we showed that CSP is significantly superior to HP in reducing DPPB after colorectal polyp 


\begin{tabular}{l|l|l|l|}
\begin{tabular}{l} 
- Table 4 Adverse events. \\
\hline
\end{tabular} & CSP group & HP group & P value \\
\hline Adverse events & $\mathrm{n}=330$ & $\mathrm{n}=209$ & \\
\hline - Delayed bleeding & 0 & 4 & $0.02^{1}$ \\
\hline - Perforation & 0 & 0 & $1.0^{1}$ \\
\hline $\begin{array}{l}\text { Adverse events after pro- } \\
\text { pensity score-matching }\end{array}$ & $\mathrm{n}=231$ & $\mathrm{n}=177$ & \\
\hline - Delayed bleeding & 0 & & \\
\hline - Perforation & 0 & 4 & 0.041 \\
\hline $\begin{array}{l}\text { CSP, cold snare polypectomy; HP, hot snare polypectomy } \\
\text { 1 Fisher's exact test }\end{array}$ & & \\
\hline
\end{tabular}

endoscopic resection. Although in previous reports, DPPB occurred less commonly after CSP [15-18], this is the first study to show this result in a large sample of patients/polyps by using propensity score matching analysis. In other words, if patients undergo HP in these clinical setting, it would cause significantly more DPPB than CSP. Hence our findings indicate that CSP is recommended polypectomy in these clinical setting.

In general, the incidence of DPPB after HP has been reportedly higher in patients receiving anticoagulation therapy [ 23 , 24] even though warfarin is interrupted prior to the HP procedure [25]. However, Horiuchi et al. also reported that DPPB requiring hemostasis occurred significantly less frequently after CSP than it did after HP despite continuation of anticoagulants. [17] In our study, we were able to remove polyps safely in eighteen patients on single anticoagulant therapy. We therefore consider that CSP has the potential to safely remove subcentimetric polyps in patients receiving single anticoagulant therapy. Conversely, in the guidelines of The American Society for Gastrointestinal Endoscopy and The European Society of Gastrointestinal Endoscopy, the risk of DPPB is low among patients undergoing HP and being treated with aspirin as antiplatelet monotherapy $[26,27]$. However, patients receiving thienopyridines were recommended to be treated as having a high risk of DPPB $[26,27]$ and some reports suggested that the DPPB rate of HP was higher in the group that continued to use thienopyridines $[28,29]$. Although Repici et al. reported that single antiplatelet therapy was an independent predictor of immediate postpolypectomy bleeding, their patients underwent CSP, including 33 patients on thienopyridines, and there were no cases of DPPB [16]. This was comparable with our study results in that we were able to remove nine polyps safely in patients on single thienopyridine therapy. In our study, we excluded patients taking two antithrombotic agents; such patients should therefore be further evaluated in a future multicenter study.

Some studies reported that the rate of histologic eradication of CSP was $93.2 \%$ to $99 \%[15,30,31]$. This is a high rate, equal to that of HP [32]. In previous reports, the evaluable horizontal margin rate of CSP was $42.2 \%$ to $60 \%$ [15,33], lower than that of the HP [33]. In our study, although we achieved a lower proportion of cases of positive horizontal margin (1.4\%), there were $24 \%$ of cases of unclear horizontal margin. We believe this may have resulted from the small crushed specimens which stem largely from our not having used a dedicated cold snare. This outcome could be improved by more extensive mucosal resection or modifying the existing cold snare. However, endoscopists should always keep in mind the difficulty of pathological margin assessment with CSP.

Furthermore, in the CSP group, polyp retrieval failure has become an issue $[34,35]$. In our study, the polyp retrieval failure rate was $4 \%$, and polyp retrieval failure was significantly more frequent in the CSP group even after propensity score matching analysis. Although we couldn't investigate in this study, this may be because the size of the resected specimen obtained with CSP is smaller than that obtained with HP by submucosal injection even though the tumor size is the same. Moreover, after CSP, there is more or less immediate bleeding, which may impair the endoscopic visibility. It was suggested in some reports that immediate polyp retrieval by suction or by pulling the polyp into the colonoscope channel, then transecting it while suctioning, yielded a high rate of polyp retrieval $[35,36]$. However, all endoscopists need to be extremely careful while performing the polyp retrieval.

We underwent clipping when the mucosal defects were large or if blood was spurting immediately. Some reports described that prophylactic clipping prevent DPPB [37-39]. In contrast, some studies have demonstrated that there was no difference [40-43]. In this study, the HP group had a significantly larger number of clips used for closure of the mucosal defect. However, there is significantly higher rate of DPPB in HP group. Many factors will affect DPPB and it is still controversial.

Our study had some limitations. First, although the study participants were prospectively enrolled into our database, the detailed data of the patients were retrospectively collected from medical records. Of course, we routinely use the same care plan for all patients undergoing HP or CSP and symptoms were recorded routinely. However, we cannot exclude the possibility of missing data in some medical records regarding patients' symptoms, such as minor delayed bleeding. Second, this study was conducted in a single municipal hospital. Although using a standardized protocol for CSP and perioperative management can provide pure results, the number of DPPB patients is insufficient because of the rate of DPPB is relatively low. And we may be not able to properly assess DPPB outcomes. This should be further evaluated in a future multicenter study. Further data in the area of optimal endoscopic technique for patients prescribed antithrombotic agents are necessary to better inform endoscopy-related decisions and implement the best clinical practices. Third, we excluded the patients undergoing HP and CSP during the same session to avoid confusion in terms of which procedure was attributable for the DPPB. However, previous reports indicated that the rate of DPPB of CSP was $0-1.8 \%$ [15-18] and our incidence of DPPB was $0 \%$. Consequently, it is considered a negligible risk if DPPB occurred in patients undergoing HP and CSP during the same session. Forth, there would be a possibility of inter-operator variability. Although all colonoscopists who participated in this study underwent both CSP and HP, some colonoscopists may prefer 
CSP to HP and conversely. However, CSP and HP is a simple and well established method, we thought it may be negligible effect on DPPB. This would be also further evaluated in a future multicenter study.

\section{Conclusion}

In conclusion, CSP is a safe method for the removal of subcentimeter polyps, and it is even a safe method for the removal of these lesions in patients receiving single anticoagulant therapy or single antiplatelet therapy. Moreover, we showed by a propensity score-matching model that DPPB occurred with less frequency after CSP than it did after HP. Our findings indicate that CSP is recommended polypectomy in daily clinical setting. However, special care should be taken during polyp retrieval and horizontal margin assessment, and these issues could be taken into account in follow-up after CSP.

\section{Acknowledgements}

The authors thank all endoscopists and our colleagues at the Department of Gastroenterology and Hepatology, Osaka Red Cross Hospital, who supported this study.

\section{Competing interests}

None

\section{References}

[1] World Health Organization. The global burden of disease: 2004 update.

[2] Ferlay J, Soerjomataram I, Ervik M et al. Cancer Incidence and Mortality Worldwide. IARC CancerBase No. 11. GLOBOCAN 2012

[3] Vogelstein B, Fearon ER, Hamilton SR et al. Genetic alterations during colorectal-tumor development. N Engl J Med 1988; 319: 525-532

[4] Zauber AG, Winawer SJ, O'Brien M] et al. Colonoscopic polypectomy and long-term prevention of colorectal-cancer deaths. N Engl J Med 2012; 366: 687-696

[5] Levin TR, Zhao W, Conell C et al. Complications of colonoscopy in an integrated health care delivery system. Ann Intern Med 2006; 145: $880-886$

[6] Sorbi D, Norton I, Conio M et al. Postpolypectomy lower GI bleeding: descriptive analysis. Gastrointest Endosc 2000; 51: 690-696

[7] Watabe H, Yamaji Y, Okamoto M et al. Risk assessment for delayed hemorrhagic complication of colonic polypectomy: polyp-related factors and patient-related factors. Gastrointest Endosc 2006; 64: $73-78$

[8] Zhang Q, An S li, Chen Z yu et al. Assessment of risk factors for delayed colonic post-polypectomy hemorrhage: a study of 15553 polypectomies from 2005 to 2013. PLoS One 2014; 9: e108290

[9] Sonnenberg A. Management of delayed postpolypectomy bleeding: a decision analysis. Am J Gastroenterol 2012; 107: 339-342

[10] Choung BS, Kim SH, Ahn DS et al. Incidence and risk factors of delayed postpolypectomy bleeding: a retrospective cohort study. J Clin Gastroenterol 2014; 48: $784-789$
[11] Tappero G, Gaia E, De Giuli P et al. Cold snare excision of small colorectal polyps. Gastrointest Endosc 1992; 38: 310-313

[12] Waye JD. New methods of polypectomy. Gastrointest Endosc Clin N Am 1997; 7: 413-422

[13] Uno Y, Obara K, Zheng P et al. Cold snare excision is a safe method for diminutive colorectal polyps. Tohoku J Exp Med 1997; 183: 243-249

[14] Ichise $Y$, Horiuchi A, Nakayama $Y$ et al. Prospective randomized comparison of cold snare polypectomy and conventional polypectomy for small colorectal polyps. Digestion 2011; 84: $78-81$

[15] Takeuchi Y, Yamashina T, Matsuura N et al. Feasibility of cold snare polypectomy in Japan: A pilot study. World J. Gastrointest Endosc 2015; 7: $1250-1256$

[16] Repici A, Hassan C, Vitetta E et al. Safety of cold polypectomy for $<10 \mathrm{~mm}$ polyps at colonoscopy : a prospective multicenter study. Endoscop 2012; 44: 27-31

[17] Horiuchi A, Nakayama $Y$, Kajiyama M et al. Removal of small colorectal polyps in anticoagulated patients: a prospective randomized comparison of cold snare and conventional polypectomy. Gastrointest Endosc 2014; 79: 417-423

[18] Park S-K, Ko BM, Han JP et al. A prospective randomized comparative study of cold forceps polypectomy by using narrow-band imaging endoscopy versus cold snare polypectomy in patients with diminutive colorectal polyps. Gastrointest Endosc 2016; 83: 527-532

[19] Paspatis GA, Tribonias G, Konstantinidis K et al. A prospective randomized comparison of cold vs hot snare polypectomy in the occurrence of postpolypectomy bleeding in small colonic polyps. Colorectal Dis 2011; 13: $345-348$

[20] Rosenbaum PR, Rubin DB. The central role of the propensity score in observational studies for causal effects. Biometrika 1983; 70: 41 - 55

[21] von Elm E, Altman DG, Egger M et al. The Strengthening the Reporting of Observational Studies in Epidemiology (STROBE) statement: guidelines for reporting observational studies. Ann Intern Med 2007; 147: $573-577$

[22] Workshop P in the P. The Paris endoscopic classification of superficial neoplastic lesions: esophagus, stomach, and colon. Gastrointest. Endosc 2003; 58: 3-43

[23] Sawhney MS, Salfiti N, Nelson DB et al. Risk factors for severe delayed postpolypectomy bleeding. Endoscopy 2008; 40: 115-119

[24] Hui AJ, Wong RM, Ching JY et al. Risk of colonoscopic polypectomy bleeding with anticoagulants and antiplatelet agents: analysis of 1657 cases. Gastrointest Endosc 2004; 59: 44-48

[25] Witt DM, Delate T, McCool KH et al. Incidence and predictors of bleeding or thrombosis after polypectomy in patients receiving and not receiving anticoagulation therapy. J Thromb Haemost 2009; 7 : $1982-1989$

[26] Acosta RD, Abraham NS, Chandrasekhara V et al. The management of antithrombotic agents for patients undergoing Gl endoscopy. Gastrointest Endosc 2016; 83: 3-16

[27] Veitch AM, Vanbiervliet G, Gershlick AH et al. Endoscopy in patients on antiplatelet or anticoagulant therapy, including direct oral anticoagulants: British Society of Gastroenterology (BSG) and European Society of Gastrointestinal Endoscopy (ESGE) guidelines. Endoscopy 2016; 48: 385-402

[28] ingh M, Mehta N, Murthy UK et al. Postpolypectomy bleeding in patients undergoing colonoscopy on uninterrupted clopidogrel therapy. Gastrointest. Endosc 2010; 71: 998 - 1005

[29] Gandhi S, Narula N, Mosleh W et al. Meta-analysis: colonoscopic postpolypectomy bleeding in patients on continued clopidogrel therapy. Aliment. Pharmacol. Ther 2013; 37: 947-952

[30] Lee CK, Shim J-J, Jang JY. Cold snare polypectomy vs. Cold forceps polypectomy using double-biopsy technique for removal of diminutive colorectal polyps: a prospective randomized study. Am. J. Gastroenterol 2013; 108: $1593-1600$ 
[31] Kim JS, Lee B-I, Choi H et al. Cold snare polypectomy versus cold forceps polypectomy for diminutive and small colorectal polyps: a randomized controlled trial. Gastrointest. Endosc 2015; 81: 741 - 747

[32] Pohl H, Srivastava A, Bensen SP et al. Incomplete polyp resection during colonoscopy-results of the complete adenoma resection (CARE) study. Gastroenterology 2013; 144: 74-80

[33] Saito D, Hayashida M, Miura M et al. A comparative study between cold nare polypectomy and endoscopic mucosal resection for resection of colorectal polyps. (In Japanese with English abstract.). Gastroenterol. Endosc 2016; 58: 32-37

[34] Komeda Y, Suzuki N, Sarah M et al. Factors associated with failed polyp retrieval at screening colonoscopy. Gastrointest. Endosc 2013; 77: $395-400$

[35] Fernandes C, Pinho R, Ribeiro I et al. Risk factors for polyp retrieval failure in colonoscopy. United Eur. Gastroenterol. J 2015; 3: 387 - 392

[36] Deenadayalu VP, Rex DK. Colon polyp retrieval after cold snaring. Gastrointest. Endosc 2005; 62: 253-256

[37] Liaquat H, Rohn E, Rex DK. Prophylactic clip closure reduced the risk of delayed postpolypectomy hemorrhage: experience in 277 clipped large sessile or flat colorectal lesions and 247 control lesions. Gastrointest. Endosc 2013; 77: 401-407
[38] Matsumoto M, Fukunaga S, Saito Y et al. Risk factors for delayed bleeding after endoscopic resection for large colorectal tumors. Jpn. J. Clin. Oncol 2012; 42: 1028-1034

[39] Zhang Q-S, Han B, Xu J-H et al. Clip closure of defect after endoscopic resection in patients with larger colorectal tumors decreased the adverse events. Gastrointest. Endosc 2015; 82: 904 - 909

[40] Shioji K, Suzuki Y, Kobayashi M et al. Prophylactic clip application does not decrease delayed bleeding after colonoscopic polypectomy. Gastrointest. Endosc 2003; 57: 691-694

[41] Boustière C, Veitch A, Vanbiervliet $G$ et al. Endoscopy and antiplatelet agents. European Society of Gastrointestinal Endoscopy (ESGE) Guideline. Endoscopy 2011; 43: 445-461

[42] Matsumoto M, Kato M, Oba K et al. Multicenter randomized controlled study to assess the effect of prophylactic clipping on post-polypectomy delayed bleeding. Dig. Endosc 2016; 28: 570-576

[43] Dokoshi T, Fujiya M, Tanaka K et al. A randomized study on the effectiveness of prophylactic clipping during endoscopic resection of colon polyps for the prevention of delayed bleeding. Biomed Res. Int 2015; 02: $1-6$ 